\title{
The one repetition maximum test and the sit- to-stand test in the assessment of a specific pulmonary rehabilitation program on peripheral muscle strength in COPD patients
}

\author{
This article was published in the following Dove Press journal: \\ International Journal of COPD \\ II November 2015 \\ Number of times this article has been viewed
}

\begin{abstract}
Andrea Zanini ${ }^{1,2}$
Marina Aiello ${ }^{3}$

Francesca Cherubino'

Elisabetta Zampogna'

Andrea Azzola ${ }^{4}$

Alfredo Chetta $^{3}$

Antonio Spanevello 1,5

'Division of Pneumology, IRCCS

Rehabilitation Institute of Tradate,

Salvatore Maugeri Foundation,

Tradate, Italy; ${ }^{2}$ Division of Internal and Respiratory Medicine, Malcantonese

Hospital, Giuseppe Rossi Foundation,

Castelrotto, Switzerland; ${ }^{3}$ Respiratory

Disease and Lung Function Unit,

Department of Clinical and

Experimental Medicine, University of

Parma, Padiglione Rasori, Parma, Italy;

${ }^{4}$ Division of Pneumology, Department of Internal Medicine, Ospedale Civico, Lugano, Switzerland; ${ }^{5}$ Department of Clinical and Experimental Medicine, University of Insubria, Varese, Italy
\end{abstract}

Correspondence: Andrea Zanini

Divisione di Medicina Interna a Indirizzo Pneumologico, Ospedale Malcantonese,

Fondazione Giuseppe Rossi, 6980

Castelrotto, Switzerland

$\mathrm{Tel}+4$ I 916113700

Fax +41 91 61 I 3701

Email azanini67@gmail.com
Background: Individuals with COPD may present reduced peripheral muscle strength, leading to impaired mobility. Comprehensive pulmonary rehabilitation (PR) should include strength training, in particular to lower limbs. Furthermore, simple tools for the assessment of peripheral muscle performance are required.

Objectives: To assess the peripheral muscle performance of COPD patients by the sit-to-stand test (STST), as compared to the one-repetition maximum (1-RM), considered as the gold standard for assessing muscle strength in non-laboratory situations, and to evaluate the responsiveness of STST to a PR program.

Methods: Sixty moderate-to-severe COPD inpatients were randomly included into either the specific strength training group or into the usual PR program group. Patients were assessed on a 30-second STST and 1-minute STST, 1-RM, and 6-minute walking test (6MWT), before and after PR. Bland-Altman plots were used to evaluate the agreement between 1-RM and STST. Results: The two groups were not different at baseline. In all patients, 1-RM was significantly related to the 30 -second STST ( $r=0.48, P<0.001)$ and to 1 -minute STST $(r=0.36, P=0.005)$. The 30 -second STST was better tolerated in terms of the perceived fatigue $(P=0.002)$ and less time consuming $(P<0.001)$ test. In the specific strength training group significant improvements were observed in the 30 -second STST $(P<0.001), 1$-minute STST $(P=0.005), 1$-RM $(P<0.001)$, and in the 6MWT $(P=0.001)$. In the usual PR program group, significant improvement was observed in the 30 -second STST $(P=0.042)$ and in the 6MWT $(P=0.001)$.

Conclusion: Our study shows that in stable moderate-to-severe inpatients with COPD, STST is a valid and reliable tool to assess peripheral muscle performance of lower limbs, and is sensitive to a specific PR program.

Keywords: sit-to-stand test, strength training, COPD

\section{Introduction}

Muscle weakness and peripheral muscle dysfunction are highly prevalent comorbidities of chronic obstructive pulmonary disease (COPD), contributing to exercise intolerance and symptom intensity. ${ }^{1,2}$ Pulmonary rehabilitation (PR) has a well-established role in the management of COPD patients with peripheral muscle dysfunction. ${ }^{3}$ Evidence-based guidelines for PR recommend that the exercise component of the program includes endurance and strength training of the lower limbs. ${ }^{4}$ Strength training has a greater potential to improve muscle mass and strength than with endurance training. ${ }^{5,6}$ In addition, strength training also induces less dyspnea during the exercise period, making this strategy better performed by patients with moderate-to-severe COPD, than with aerobic training.? 
The one-repetition maximum (1-RM) strength test is defined as the maximal weight that can be lifted once by proper lifting technique ${ }^{8,9}$ using a resistance machine. 1-RM is considered as the gold standard for assessing muscle strength in non-laboratory situations. ${ }^{8,9}$ The 1-RM is a welltolerated test by patients included in PR programs ${ }^{10}$ and has been recently used to evaluate the muscle strength assessment in individuals with COPD. ${ }^{11,12}$ However, the test requires trained personnel and equipment, with unavoidable expenditure in terms of time that may prevent widespread use in health care settings. Quick and easy tools to obtain valid and reliable muscle strength outcomes in most clinical settings, including rehabilitation centers, are needed.

The sit-to-stand test (STST) represents a viable alternative for measuring peripheral muscle strength of the lower limbs. ${ }^{13}$ Variations of the STST include the maximum number of times a subject can stand up and sit down on a regular chair in a given period of time, usually 30 -seconds or 1-minute, ${ }^{14,15}$ or the time taken to perform a given number of sit-to-stand maneuvers. ${ }^{16}$ The STST can be performed in any health care setting, since it requires minimal equipment (conventional chair and stopwatch) and is easy and quick to perform for most subjects.

Accordingly, the aim of this study was to assess the peripheral muscle performance of the lower limbs in COPD patients by two STSTs (30-seconds and 1-minute), as compared to the 1-RM, and to evaluate the responsiveness of STSTs and 1-RM to a PR program with specific strength training (SPR), compared to usual PR program (UPR).

\section{Methods}

\section{Design of the study}

Firstly, COPD patients were examined in a cross-sectional strategy, to compare 1-RM and the two STSTs in assessing lower muscle performance at baseline. Accordingly, on day 1 of the study, patients performed medical evaluation (medical history and physical examination), pulmonary function tests, and blood gas analysis. On the subsequent day, in the afternoon, patients performed a 6-minute walking test (6MWT) and 1-RM, with an interval of at least 2 hours between each test. On day 3 , in the afternoon, patients performed the two STSTs, with an interval of at least 2 hours between each test.

Secondly, patients were randomly allocated into either the intervention group receiving SPR or into the UPR group. Before discharge, patients repeated functional assessments. Differences between initial and final values were calculated.

The study was approved by the Internal Review Board of the Institute of Care and Scientific Research Rehabilitation Institute of Tradate, Salvatore Maugeri Foundation, Tradate,
Italy. The procedures were performed between January 7 , 2014 to April 9, 2015.

\section{Subjects}

We examined 60 patients with COPD who attended an inpatient PR program. The majority of patients were sedentary and housebound. Twenty-four out of 60 patients participated in a previous PR program, but all these patients were free from this PR program for at least 1 year and they were present in both intervention groups, without any statistically significant difference. Thirty subjects were randomly assigned into the SPR group and 30 in the UPR group, and the two groups matched for age, sex, and disease severity. All patients had a diagnosis for COPD according to the Global initiative for chronic Obstructive Lung Disease (GOLD) criteria. ${ }^{17}$ Patients who had acute exacerbation over the previous 4 weeks were excluded. Patients who did not complete the PR program, for intercurrent COPD exacerbation, or any unstable medical condition, were also excluded. Contraindications for participation in the PR program included musculoskeletal disorders, malignant diseases, unstable cardiac condition, and lack of adherence to the program. All patients had a smoking history $\geq 10$ pack years and received regular treatment with inhaled bronchodilators and inhaled steroids according to current guidelines for their disease stage. Each patient signed an informed consent form.

\section{Pulmonary function tests and arterial blood gas analysis}

Vital capacity (VC), forced expiratory volume in 1 second $\left(\mathrm{FEV}_{1}\right)$, total lung capacity (TLC), and residual volume (RV) were measured by means of a flow-sensing spirometer and a body plethysmograph connected to a computer for data analysis (Masterlab, Jaeger, Wurzburg, Germany). Transfer factor of the lung for carbon monoxide ( $T \mathrm{~L}, \mathrm{CO}$ ) was measured by the single breath method using a mixture of carbon monoxide and methane (Sensor Medics, Yorba Linda, USA). VC, FEV 1 TLC, RV, and $T \mathrm{~L}, \mathrm{CO}$ were expressed as a percentage of the predicted values, which were obtained from regression equations by Quanjer et a ${ }^{18}$ and Cotes et al. $.^{19} \mathrm{FEV}_{\mathrm{l}} / \mathrm{VC}$ and RV/TLC ratios were taken as indices of airway obstruction and lung hyperinflation, respectively.

Arterial partial pressure of oxygen and arterial partial pressure of carbon dioxide were measured immediately after sampling from a puncture of the radial artery (Gas analyzer ABL 330; Radiometer, Copenhagen, Denmark).

\section{I-RM test}

The 1-RM strength test was performed using a resistance weight-lifting machine (Leg Extension, Mod. Class 2Sc, 
Technogym, Cesena, Italy). Prior to muscular strength testing, all patients were instructed on the proper technique. Briefly, each subject was instructed in sitting position to extend both knees at the same time, starting from a $90^{\circ}$ knee flexion position to a $180^{\circ}$ extension, which works the thigh muscles, and especially the quadriceps. Prior to performing the 1-RM testing sessions, all participants underwent two familiarization sessions without any load. This 1-RM strength test was to determine the greatest amount of weight that the individual could move in a single repetition, with a random initial load that was increased or reduced in accordance with the individual's ability to perform a repetition; this could be repeated again, with a 1-minute interval between each load. ${ }^{9}$

\section{STST}

A straight-backed armless chair with a hard seat was stabilized by placing it against a wall. Floor to seat height was $47 \mathrm{~cm}$. Seated participants were asked to come forward on the seat until their feet were flat on the floor, and to fold their upper limbs across the chest. Participants were then instructed to stand up all the way and sit down once without using the upper limbs. Subjects started in the seated position on the chair and, upon command, stood up and then returned to sitting as many times as possible in a 30 -second time period and in a 1-minute time period. ${ }^{14,15}$

\section{VAS fatigue}

Immediately after 1-RM and STSTs, patients rated the magnitude of their perceived peripheral muscle fatigue to complete the test. We adopted an interval scale, which was a $100 \mathrm{~mm}$ horizontal visual analogue scale (VAS), ranging from 0 (no fatigue) to 100 (worst imaginable fatigue). ${ }^{20}$ The subjects had to indicate their lower limbs muscle fatigue perception at the moment of the assessment.

\section{Walking capacity}

Walking capacity was evaluated by means of the distance covered during a 6MWT according to the American Thoracic Society (ATS) statement. ${ }^{21}$ The 6MWT was performed by all patients in a $30 \mathrm{~m}$ indoor, level, hospital corridor, under the supervision of a physiotherapist, according to the ATS guidelines. All patients received the same instructions before the walk, and were encouraged by the physiotherapist who repeated set phrases every minute during the walk. A practice $6 \mathrm{MWT}$ was not performed. The distance covered during the test was recorded in meters. Patients were allowed to stop and rest during the test but were instructed to resume walking as soon as they felt able to do so.

\section{PR program}

The control and the intervention group received the UPR. According to the international recommendations, the PR program was completely tailored to suit the needs of the individual. ${ }^{3}$ The program consisted of 15 sessions over a 3-week period. To be included in the study, patients had to perform at least 12 supervised sessions, up to a maximum of 15 sessions. Lower limb endurance training was the main component of the PR program. All patients performed sessions of 30-40 minutes, using a treadmill or cycle-ergometer, depending on the clinically based choice of the physiotherapist, and on the subject's preference. Exercise intensity was based on the initial 6MWT, and patients started their training at 60\%-70\% of the maximum heart rate (HR) achieved on the 6MWT. ${ }^{22}$ Exercises were then adjusted based on patient tolerance (at least weekly) with the aim of achieving a Borg dyspnea score of 3-5 (moderate-severe). To optimize training load supplemental oxygen for patients with chronic respiratory failure and interval training for much compromised patients were adopted. Transcutaneous arterial oxygen saturation, arterial pressure, and HR were monitored during every exercise session. Each session also included supervised upper limb training; patients used an arm ergometer or performed callisthenic exercises holding a light weight. In relation to the patient's needs, the PR program could also include other components, such as airway clearance techniques, pursed lips breathing and exhalation on effort, and inspiratory muscle training using threshold loading devices. Finally, each patient participated in educational activities, individually (at least one time) and in a group (at least three times), regarding self-management, airway clearance techniques, adherence to therapy, and nutritional support. The total daily time duration for all activities was 2-3 hours, and the entire program was conducted in the hospital.

In addition, the intervention group received a SPR of their peripheral muscles. The program consisted of two sets of seven different exercises, 12-20 repetitions each. Initial loads were equivalent to either $60 \%-70 \%$ of the $1-\mathrm{RM}$ or one that evoked fatigue after $8-12$ repetitions. The exercise dosage was increased when the individual could perform the current workload for one or two repetitions over the requested number on two consecutive training sessions.

\section{Statistical analysis}

Continuous data are reported as mean \pm standard deviation, unless otherwise specified. The distribution of variables was assessed by means of the Kolmogorov-Smirnov Goodness-ofFit test. ${ }^{23}$ Given the exploratory nature of the study, we did not 
evaluate the effect size. Comparisons between quantitative and qualitative variables were determined by paired and unpaired $t$-tests, and $\chi^{2}$ test, when appropriate. A statistical analysis by one way analysis of variance (ANOVA) was also performed to detect significant variations between groups, followed, where significant, by the Student's $t$-test with Bonferroni adjustment. Relationships between variables were assessed by the Pearson's correlation coefficient $(r)$. The agreement between 1-RM and STSTs was assessed by the method of differences against the means according to Bland and Altman. ${ }^{24}$ To minimize the relationship between differences and means, the difference between measures was expressed as percentage of the mean. A $P$-value $<0.05$ was considered as statistically significant.

Data analyses and graphical presentations were performed using GraphPad Prism 5 (GraphPad Software, San Diego, California, USA) and SPSS version 20 (IBM, Armonk, New York, USA).

\section{Results}

All patients completed the procedures without any dropout. Characteristics of patients at baseline are reported in Table 1. The two groups were comparable at baseline.

In all patients, at baseline 1-RM was significantly related to the 30 -second STST $(r=0.48 ; P<0.001)$ and to the 1-minute $\operatorname{STST}(r=0.36 ; P=0.005)$ (Figure 1$)$. Similarly, $6 \mathrm{MWT}$ was significantly related to the 30 -second STST $(r=0.44 ; P<0.001)$ and to the 1 -minute STST $(r=0.48$; $P<0.001)$. The relationship between baseline variables and the three outcomes evaluating peripheral muscle strength are shown in Table 2. Overall, the three outcome measures were directly related to airflow obstruction and negatively related to lung hyperinflation.

According to the Bland-Altman plots, the biases (limits of agreement) between 1-RM and 30-second STST and between $1-\mathrm{RM}$ and 1 -minute STST were $26 \%(-32 \%-85 \%)$ and $80 \%$ (32\%-128\%), respectively (Figure 2).

By ANOVA there were statistically significant differences in VAS for fatigue among 1-RM, 30-second STST, and 1-minute STST $(P=0.002)$. Post hoc analyses showed statistically significant differences between the perceived fatigue after 30 -second STST (40 \pm 26$)$ and those after both $1-\mathrm{RM}(50 \pm 28)$ and 1 -minute STST $(58 \pm 26)(P=0.047$ and $P<0.001$, respectively) (Table 3 ). The other comparisons between the three tests, regarding HR, oxygen saturation, and time required to complete the tests are shown in Table 3.

After PR, in the SPR group significant improvements were observed in 30-second STST $(P<0.001)$, 1-minute $\operatorname{STST}(P=0.005), 1-\mathrm{RM}(P<0.001)$, and 6MWT $(P=0.001)$ whereas in the UPR group significant improvement was

Table I Baseline characteristics of the two groups of COPD patients following SPR program and UPR program

\begin{tabular}{|c|c|c|c|}
\hline & $\begin{array}{l}\text { SPR group of patients } \\
(n=30)\end{array}$ & $\begin{array}{l}\text { UPR group of patients } \\
(n=30)\end{array}$ & $P$-value \\
\hline Age (years) & $69 \pm 5.8$ & $72 \pm 8$ & 0.143 \\
\hline Sex, female (\%) & $5(16.7)$ & $6(20)$ & 0.738 \\
\hline BMI $\left(\mathrm{kg} / \mathrm{m}^{2}\right)$ & $25 \pm 4$ & $26 \pm 5$ & 0.165 \\
\hline Smoking (pack years) & $53 \pm 31$ & $58 \pm 36$ & $0.57 \mid$ \\
\hline $\mathrm{FEV}_{1}(\%$ pred $)$ & $46 \pm 14$ & $51 \pm 16$ & 0.192 \\
\hline VC (\% pred) & $8 I \pm 16$ & $81 \pm 15$ & 0.918 \\
\hline $\mathrm{FEV}_{1} / \mathrm{VC}(\%)$ & $40 \pm 12$ & $44 \pm 12$ & 0.269 \\
\hline RV (\% pred) & $191 \pm 48$ & $176 \pm 46$ & 0.211 \\
\hline TLC (\% pred) & $129 \pm 20$ & $125 \pm 25$ & 0.540 \\
\hline RV/TLC (\%) & $61 \pm 9$ & $60 \pm 8$ & 0.793 \\
\hline TL,CO (\% pred) & $52 \pm 13$ & $50 \pm 13$ & 0.433 \\
\hline $\mathrm{PaO}_{2}(\mathrm{mmHg})$ & $74 \pm 7$ & $7 I \pm 7$ & 0.159 \\
\hline $\mathrm{PaCO}_{2}(\mathrm{mmHg})$ & $37 \pm 4$ & $38 \pm 5$ & 0.234 \\
\hline Exacerbations previous year (n) & $1.1 \pm 1.3$ & $1.2 \pm 1.4$ & 0.902 \\
\hline I-RM (kg) & $33 \pm 7$ & $30 \pm 10$ & 0.212 \\
\hline I-minute STST (n) & $24 \pm 4$ & $23 \pm 5$ & 0.237 \\
\hline 30-second STST (n) & $13 \pm 3$ & $13 \pm 2$ & 0.731 \\
\hline 6MWT (m) & $450 \pm 84$ & $417 \pm 92$ & 0.154 \\
\hline
\end{tabular}

Notes: Values are expressed as mean \pm SD or percent. Comparisons between variables were determined by unpaired $t$-test and $\chi^{2}$ test. The two groups were matched for age, sex, and disease severity.

Abbreviations: SD, standard deviation; $\mathrm{FEV}_{1}$, forced respiratory volume in I second; VC, vital capacity; RV, residual volume; TLC, total lung capacity; TL, CO, transfer factor of the lung for carbon monoxide; $\mathrm{BMI}$, body mass index; $\mathrm{PaO}_{2}$, arterial partial pressure of oxygen; $\mathrm{PaCO}_{2}$, arterial partial pressure of carbon dioxide; I-RM, one-repetition maximum; STST, sit-to-stand test; 6MWT, 6-minute walking test; pred, predicted; SPR, specific pulmonary rehabilitation; UPR, usual pulmonary rehabilitation. 

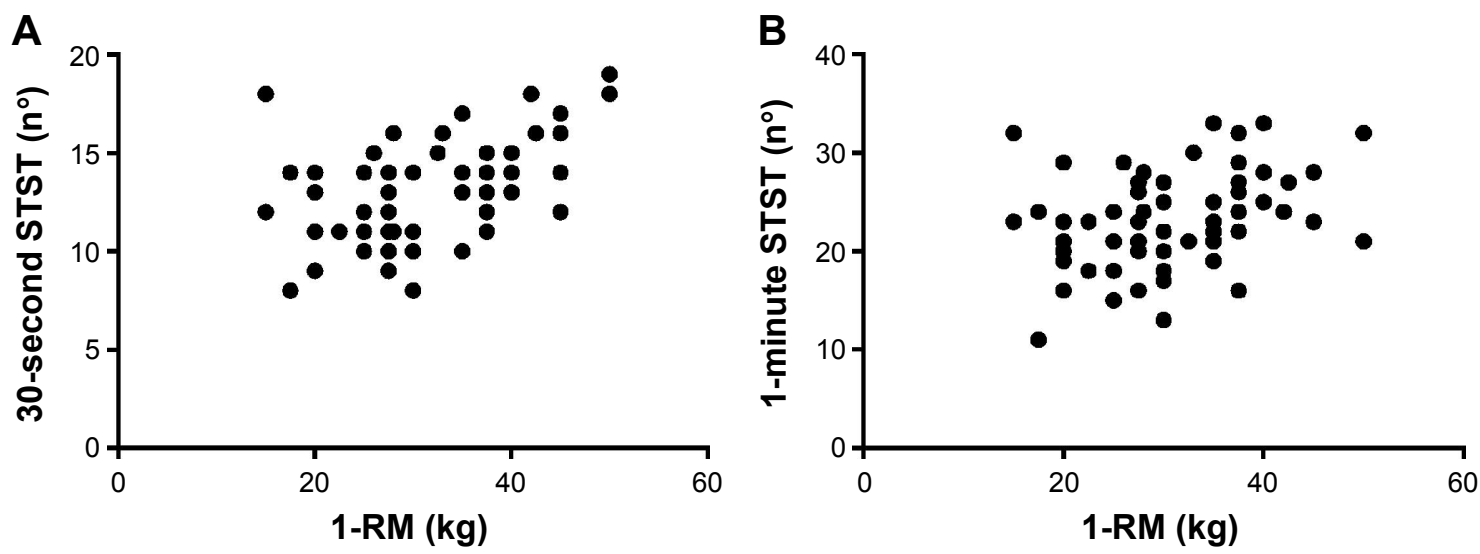

Figure I Relationship between the I-RM and the two STSTs, 30-seconds $(r=0.48, P<0.00 \mathrm{I})(\mathbf{A})$ and I-minute $(r=0.36, P=0.005)(\mathbf{B})$ at baseline in $60 \mathrm{COPD}$ patients. Abbreviations: STST, sit-to-stand test; I-RM, one-repetition maximum.

observed in 30-second STST $(P=0.042)$ and $6 \mathrm{MWT}$ $(P=0.001)$ (Table 4).

In the SPR group, the improvement in 30-second STST after PR, expressed as a percent change, but not in 1-minute STST, was directly correlated with the change in 1-RM ( $r=0.47 ; P=0.009)$.

\section{Discussion}

In this study, we investigated the value of the STST in the assessment of the peripheral muscle strength of lower limbs, by comparing it to the 1-RM and by evaluating its responsiveness to a specific PR program in patients with stable moderate-to-severe COPD. The main result of this study was that in all patients, 30-second STST and 1-minute STST showed a significant correlation with 1-RM, considered as the gold standard for muscle strength assessing. Moreover, only the specific PR program was able to significantly improve the 30-second STST and 1-minute STST, and 1-RM. Finally, as compared to 1-minute STST and 1-RM, 30-second STST was better tolerated in terms of perceived fatigue and quicker to perform in terms of expenditure of time, including instructions to the patient.

It has been recognized that skeletal muscle dysfunction is a common feature in patients with COPD, and may play a significant role in morbidity and mortality. ${ }^{25,26}$ Several studies have demonstrated that peripheral muscle weakness may be a major contributor to exercise limitation in COPD. ${ }^{1,27}$ Although 1-RM is the most reliable test for evaluating the maximal strength of a muscle or group of muscles, ${ }^{8,9}$ untrained subjects are not always able to reach

Table 2 Relationship between baseline variables and the three outcomes of peripheral muscle strength, 30-second STST and I-minute STST and I-RM, in all study patients

\begin{tabular}{|c|c|c|c|}
\hline & 30-second STST & I-minute STST & I-RM \\
\hline Age (years) & $r=-0.21 ; P=0.104$ & $r=-0.22 ; P=0.091$ & $r=-0.25 ; P=0.052$ \\
\hline BMI $\left(\mathrm{kg} / \mathrm{m}^{2}\right)$ & $r=0.08 ; P=0.521$ & $r=-0.01 ; P=0.940$ & $r=0.21 ; P=0.102$ \\
\hline Exacerbations previous year $(n)$ & $r=0.01 ; P=0.914$ & $r=-0.04 ; P=0.765$ & $r=-0.15 ; P=0.267$ \\
\hline Pack years $(n)$ & $r=-0.01 ; P=0.991$ & $r=-0.12 ; P=0.352$ & $r=-0.1 \mathrm{I} ; P=0.4 \mathrm{I} 4$ \\
\hline $\mathrm{FEV}_{1}$ (\% pred) & $r=0.38 ; P=0.002$ & $r=0.46 ; P<0.00 I$ & $r=0.38 ; P=0.002$ \\
\hline VC (\% pred) & $r=0.37 ; P=0.003$ & $r=0.48 ; P<0.001$ & $r=0.37 ; P=0.003$ \\
\hline $\mathrm{FEV}_{1} / \mathrm{VC}$ & $r=0.26 ; P=0.044$ & $r=0.31 ; P=0.015$ & $r=0.24 ; P=0.06 \mathrm{I}$ \\
\hline RV (\% pred) & $r=-0.24 ; P=0.062$ & $r=-0.14 ; P=0.304$ & $r=-0.13 ; P=0.341$ \\
\hline TLC (\% pred) & $r=0.09 ; P=0.497$ & $r=0.23 ; P=0.078$ & $r=-0.22 ; P=0.086$ \\
\hline $\mathrm{RV} / \mathrm{TLC}$ & $r=-0.36 ; P=0.004$ & $r=-0.26 ; P=0.042$ & $r=-0.49 ; P<0.00 I$ \\
\hline TL,CO (\% pred) & $r=0.13 ; P=0.323$ & $r=0.38 ; P=0.003$ & $r=0.27 ; P=0.035$ \\
\hline $\mathrm{PaO}_{2}(\mathrm{mmHg})$ & $r=0.11 ; P=0.388$ & $r=0.27 ; P=0.039$ & $r=0.03 ; P=0.809$ \\
\hline $\mathrm{PaCO}_{2}(\mathrm{mmHg})$ & $r=-0.06 ; P=0.629$ & $r=-0.12 ; P=0.356$ & $r=-0.16 ; P=0.228$ \\
\hline
\end{tabular}

Notes: Relationships between variables were assessed by the Pearson's correlation coefficient ( $r$ ). Values in bold type significant correlations.

Abbreviations: $\mathrm{FEV}_{1}$, forced respiratory volume in I second; VC, vital capacity; RV, residual volume; TLC, total lung capacity; TL,CO, transfer factor of the lung for carbon monoxide; $\mathrm{BMI}$, body mass index; $\mathrm{PaO}_{2}$, arterial partial pressure of oxygen; $\mathrm{PaCO}_{2}$, arterial partial pressure of carbon dioxide; I-RM, one-repetition maximum; STST, sit-to-stand test. 
A

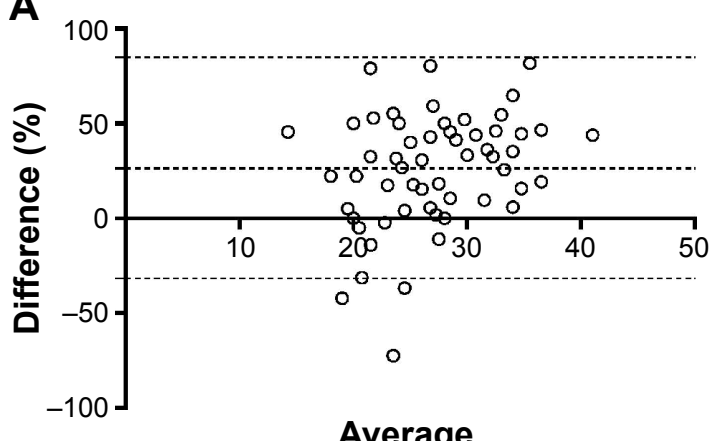

B

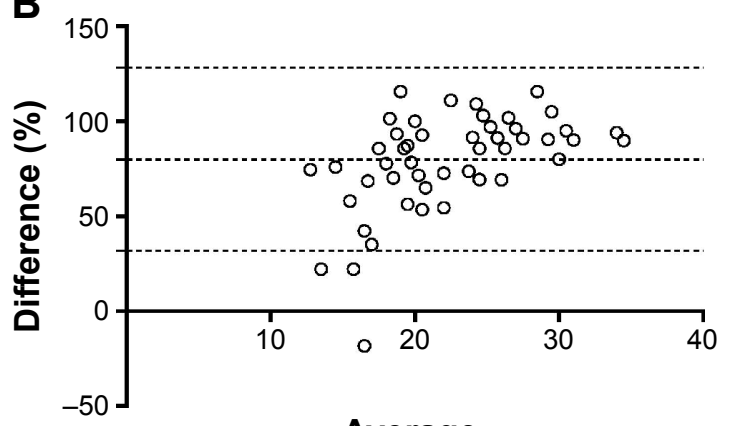

Average

Figure 2 Plot of the percentage difference between I-RM and 30-second STST against the mean of I-RM and 30-second STST (A), and plot of the percentage difference between I-RM and I-minute STST against the mean of I-RM and I-minute STST (B) in 60 COPD patients.

Abbreviations: STST, sit-to-stand test; I-RM, one-repetition maximum.

their 1-RM. ${ }^{25}$ Therefore, a familiarization process prior to 1-RM strength test is essential for ensuring reliable test results, and minimize learning effects or systematic bias. ${ }^{28}$ Moreover, multiple familiarization sessions are needed to avoid an improvement in muscle strength due to improved motor coordination or other neural adaptations. ${ }^{29}$ Despite being one of the most common tests used in clinical practice for exercise prescription in healthy subjects, proper assessment using 1-RM is time consuming and may lead to muscle fatigue. ${ }^{30}$

The STST was found to be a reliable tool to assess lower body strength and performance ${ }^{13-16}$ and might be considered as an alternative tool to $1-\mathrm{RM} .{ }^{14}$ Interestingly, Jones et al ${ }^{14}$ determined the test-retest reliability of the 30 -second chair stand, as a measure of lower body strength in 76 healthy older adults with a mean age of 74 years, and tested its validity by comparing chair-stand performance to 1-RM. They showed a good test-retest intraclass correlation and a highly significant correlation between chair-stand and 1-RM leg-press performance. ${ }^{14}$ In addition, Takai et al evaluated
57 elderly healthy subjects with a mean age of 64 years and showed that a combined power index of a ten repeated STST, including time taken for the test, body mass and leg length, can assess the force-generating capacity of knee extensors. ${ }^{31}$ However, to the best of our knowledge, no previous studies have so far been addressed to compare STST to 1-RM in COPD patients.

In the present study, we provided the first evidence of a significant correlation between STST and 1-RM kneeextension in a population of COPD clinically stable patients. Notably, the 30-second STST showed a better relationship with 1-RM than 1-minute STST. We also found that the 30 -second STST was better tolerated and quicker to be performed by the patients. These findings may have some practical interest. Laboratory tests are expensive, labor intensive, and require specialist equipment and personnel. Moreover, unlike 1-RM, the STST maneuver is simpler, cheaper, and represents a common activity of daily living.

In addition, we demonstrated a significant relationship between lung function and the performance data of the three

Table 3 Comparisons between the two STSTs and I-RM with respect to VAS fatigue at the end of the test, HR, SpO , and time required to complete the test

\begin{tabular}{|c|c|c|c|c|c|c|}
\hline & 30-second STST & I-minute STST & I-RM & $P$-value ${ }^{\S}$ & $P$-value & $P$-value* \\
\hline VAS fatigue & $40 \pm 26$ & $58 \pm 26$ & $50 \pm 29$ & 0.047 & 0.122 & $<0.001$ \\
\hline HR at rest (bpm) & $83 \pm 13$ & $83 \pm 13$ & $82 \pm 13$ & 0.620 & 0.847 & 0.765 \\
\hline HR max (bpm) & $101 \pm 13$ & $99 \pm 15$ & $92 \pm 14$ & $<0.001$ & 0.013 & 0.382 \\
\hline$\Delta \mathrm{HR}(\mathrm{bpm})$ & $18 \pm 9$ & $16 \pm 11$ & $10 \pm 8$ & $<0.001$ & $<0.001$ & 0.412 \\
\hline $\mathrm{SpO}_{2}$ at rest & $95 \pm 2$ & $94 \pm 2$ & $94 \pm 2$ & 0.003 & 0.713 & 0.009 \\
\hline $\mathrm{SpO}_{2}(\mathrm{~min})$ & $93 \pm 2$ & $92 \pm 3$ & $92 \pm 2$ & 0.019 & 0.428 & 0.003 \\
\hline$\Delta \mathrm{SpO}_{2}$ & $2 \pm 1.8$ & $2.6 \pm 2$ & $2 \pm 1.5$ & 0.911 & 0.103 & 0.157 \\
\hline Time (sec) & $120 \pm 32$ & $164 \pm 46$ & $491 \pm 145$ & $<0.001$ & $<0.001$ & $<0.001$ \\
\hline
\end{tabular}

Notes: Values are expressed as mean \pm SD. Comparisons between variables were determined by ANOVA, followed by the Student's $t$-tests with Bonferroni adjustment. \$30-second STST vs I-RM; \#I-minute STST vs I-RM; *30-second STST vs I-minute STST.

Abbreviations: I-RM, one-repetition maximum; STST, sit-to-stand test; 6MWT, 6-minute walking test; VAS, visual analogic scale; HR, heart rate; SpO 2 , oxygen saturation; $\mathrm{SD}$, standard deviation; vs, versus; $\Delta \mathrm{HR}$, change after test in heart rate; $\Delta \mathrm{SpO}_{2}$, oxygen saturation. 
Table 4 Response to PR in the COPD patients following the SPR program and the UPR program

\begin{tabular}{|c|c|c|c|c|c|c|}
\hline \multirow[t]{2}{*}{ Outcome } & \multicolumn{3}{|c|}{ SPR group $(n=30)$} & \multicolumn{3}{|c|}{ UPR group $(n=30)$} \\
\hline & Pre-PR & Post-PR & $P$-value & Pre-PR & Post-PR & $P$-value \\
\hline I-RM (kg) & $33 \pm 7$ & $43 \pm 13$ & $<0.001$ & $30 \pm 10$ & $32 v 10$ & 0.086 \\
\hline I-minute STST (n) & $24 \pm 4$ & $26 \pm 6$ & 0.005 & $23 \pm 5$ & $24 \pm 7$ & 0.111 \\
\hline 30-second STST (n) & $13 \pm 3$ & $15 \pm 3$ & $<0.001$ & $13 \pm 2$ & $14 \pm 3$ & 0.042 \\
\hline 6MWT (m) & $450 \pm 84$ & $479 \pm 89$ & 0.001 & $417 \pm 92$ & $454 \pm 8$ & 0.001 \\
\hline
\end{tabular}

Notes: Values are expressed as mean \pm SD. Comparisons between variables were determined by paired $t$-test.

Abbreviations: I-RM, one-repetition maximum; STST, sit-to-stand test; 6MWT, 6-minute walking test; PR, pulmonary rehabilitation; SD, standard deviation; SPR, specific pulmonary rehabilitation; UPR, usual pulmonary rehabilitation.

tests. Albeit with some differences among the three strength tests, the patients with a better preserved pulmonary function were associated with a higher lower limb strength performance. Previous studies showed discordant results. ${ }^{15,16}$ No correlation between pulmonary function, expressed as $\mathrm{FEV}_{1}$, and lower limb strength performance, evaluated by 1-minute STST ${ }^{15}$ or five repetition STST ${ }^{16}$ was reported. On the other hand, Bernard et al found that quadriceps strength, measured during dynamic contractions against a hydraulic resistance, correlated positively with $\mathrm{FEV}_{1}$ expressed as percentage of predicted. ${ }^{32}$ Moreover, Seymour et al reported that the highest prevalence of quadriceps weakness, evaluated by isometric quadriceps maximum voluntary contraction strength, was found in COPD patients with the most severe airflow obstruction. ${ }^{33}$

In this study, we found a significant improvement in all the three muscle strength outcomes in the intervention PR group of COPD patients, whereas the effect of conventional PR on lower limb muscle strength had a modest, even if significant change, only in 30-second STST. Previous studies compared the effects of strength and endurance training in patients with COPD, without using STST. . $^{57,34}$ Strength training has a greater potential to improve muscle mass and strength than endurance training. ${ }^{5,6,34}$ Moreover, strength training induces less dyspnea during exercise, which most likely makes it easier to tolerate than with aerobic training. ${ }^{7}$

Despite reporting original findings with potential clinical significance, this study has some limitations. We have to acknowledge that sit-to-stand performance can depend, in addition to strength, on sensation, balance, and psychological status, as showed in older people. ${ }^{35}$ However, quadriceps strength was found to be an important factor in explaining a considerable part of the variance in sit-to-stand performance. ${ }^{35}$ In this study, we evaluated a relatively small cohort of COPD patients. Interestingly, most of the previous studies enrolled similar numbers of patients, ${ }^{9-12,14,15,28,29,31,32,34}$ whereas few studies analyzed larger cohorts of patients. ${ }^{16,25,35}$

\section{Conclusion}

In conclusion, STSTs correlated with quadriceps strength measured by 1-RM and were responsive to PR with SPR. The 30 -second STST was better tolerated in terms of perceived fatigue and quicker to perform.

\section{Acknowledgment}

We gratefully acknowledge the technical assistance of Dr Daniele Ferrari and Davide Partegiani of the University of Insubria, Varese, Italy, with preparing the manuscript.

\section{Author contributions}

$\mathrm{AZ}, \mathrm{MA}, \mathrm{AA}, \mathrm{AC}$, and AS contributed to design, drafting, and interpretation, FC and EZ collected data, AZ, FC, and EZ performed statistical analysis. All authors contributed to the revision of the paper and agree to be accountable for all aspects of the work.

\section{Disclosure}

All the authors concurred with the submission and they report no conflicts of interest in this work. No additional and/or external funding was used to support this study.

\section{References}

1. Gosselink R, Troosters T, Decramer M. Peripheral muscle weakness contributes to exercise limitation in COPD. Am J Respir Crit Care Med. 1996;153(3):976-980.

2. Hamilton AL, Killian KJ, Summers E, Jones NL. Muscle strength, symptom intensity, and exercise capacity in patients with cardiorespiratory disorders. Am J Respir Crit Care Med. 1995;152(6 Pt 1):2021-2031.

3. Spruit MA, Singh SJ, Garvey C, et al; An official American Thoracic Society/ European Respiratory Society statement: key concepts and advances in pulmonary rehabilitation. Am J Respir Crit Care Med. 2013;188(8):e13-e64.

4. Gloeckl R, Marinov B, Pitta F. Pratical recommendations for exercise training in patients with COPD. Eur Respir Rev. 2013;22(128):178-186.

5. Spruit MA, Gosselink R, Troosters T, De Paepe K, Decramer M. Resistance versus endurance training in patients with COPD and peripheral muscle weakness. Eur Respir J. 2002;19(6):1072-1078.

6. Ortega F, Toral J, Cejudo P, et al. Comparison of effects of strength and endurance training in patients with chronic obstructive pulmonary disease. Am J Respir Crit Care Med. 2002;166(5):669-674.

7. Simpson K, Killian K, McCartney N, Stubbing DG, Jones NL. Randomised controlled trial of weightlifting exercise in patients with chronic airflow limitation. Thorax. 1992;47(2):70-75. 
8. Kraemer W, Fry A. Strength testing: Development and evaluation of methodology. In: Maud PJ, Foster C, editors. Physiological assessment of human fitness. 2nd ed. Champaign, IL: Human Kinetics; 1995:115-138.

9. Levinger I, Goodman C, Hare DL, Jerums G, Toia D, Selig S. The reliability of the 1RM strength test for untrained middle-aged individuals. J Sci Med Sport. 2009;12(2):310-316.

10. Kaelin ME, Swank AM, Adams KJ, Barnard KL, Berning JM, Green A. Cardiopulmonary responses, muscle soreness, and injury during the one repetition maximum assessment in pulmonary rehabilitation patients. J Cardiopulm Rehabil. 1999;19(6):366-372.

11. Marino DM, Marrara KT, Ike D, De Oliveira AD Jr, Jamami M, Di Lorenzo VA. Study of peripheral muscle strength and severity indexes in individuals with chronic obstructive pulmonary disease. Physiother Res Int. 2010;15(3):135-143.

12. Márquez-Martín E, Ramos PC, López-Campos JL, et al. Components of physical capacity in patients with chronic obstructive pulmonary disease: relationship with phenotypic expression. Int J Chron Obstruct Pulmon Dis. 2011;6:105-112.

13. Bohannon RW. Sit-to-stand test for measuring performance of lower extremity muscles. Percept Mot Skills. 1995;80(1):163-166.

14. Jones CJ, Rikli RE, Beam WC. A 30-s chair-stand test as a measure of lower body strength in community-residing older adults. Res $Q$ Exerc Sport. 1999;70(2):113-119.

15. Ozalevli S, Ozden A, Itil O, Akkoclu A. Comparison of the sit-to-stand test with 6 min walk test in patients with chronic obstructive pulmonary disease. Respir Med. 2007;101(2):286-293.

16. Jones SE, Kon SSC, Canavan JL, et al. The five-repetition sit-to-stand test as a functional outcome measure in COPD. Thorax. 2013;68(11): 1015-1020.

17. Vestbo J, Hurd SS, Agustí AG, et al. Global strategy for the diagnosis, management, and prevention of chronic obstructive pulmonary disease: GOLD executive summary. Am J Respir Crit Care Med. 2013;187: 347-365.

18. Quanjer PH, Tammeling GJ, Cotes JE, Pedersen OF, Peslin R, Yernault JC. Lung volumes and forced ventilatory flows. Report Working Party Standardization of Lung Function Tests, European Community for Steel and Coal. Official Statement of the European Respiratory Society. Eur Respir J Suppl. 1993;16:5-40.

19. Cotes JE, Chinn DJ, Quanjer PH, Roca J, Yernault JC. Standardization of the measurement of transfer factor (diffusing capacity). Report Working Party Standardization of Lung Function Tests, European Community for Steel and Coal. Official Statement of the European Respiratory Society. Eur Respir J Suppl. 1993;16:41-52.

20. Stendardi L, Grazzini M, Gigliotti F, Lotti P, Scano G. Dyspnea and leg effort during exercise. Respir Med. 2005;99(8):933-942.
21. No author. ATS statement: guidelines for the six-minute walk test. ATS Committee on Proficiency Standards for Clinical Pulmonary Function Laboratories. Am J Respir Crit Care Med. 2002;166(1):111-117.

22. Zainuldin MR, Knoke D, Mackey MG, Luxton N, Alison JA. Prescribing cycle training intensity from the six-minute walk test for patients with COPD. BMC Pulm Med. 2007;7:9.

23. Chakravarti IM, Laha RG, Roy J. Handbook of Methods of Applied Statistics, Volume I. John Wiley and Sons, Hoboken, 1967, pp. 392-394.

24. Bland JM, Altman DG. Statistical methods for assessing agreement between two methods of clinical measurement. Lancet. 1986;1(8476): 307-310.

25. Swallow EB, Reyes D, Hopkinson NS, et al. Quadriceps strength predicts mortality in patients with moderate to severe chronic obstructive pulmonary disease. Thorax. 2007;62(2):115-120.

26. Puhan MA, Siebeling L, Zoller M, Muggensturm P, ter Riet G. Simple functional performance tests and mortality in COPD. Eur Respir J. 2013; 42(4):956-963.

27. Debigaré R, Maltais $\mathrm{F}$. The major limitation to exercise performance in COPD is lower limb muscle dysfunction. J Appl Physiol (1985). 2008; 105(2):751-753.

28. Braith RW, Graves JE, Leggett SH, Pollock ML. Effect of training on the relationship between maximal and submaximal strength. Med Sci Sports Exerc. 1993;25(1):132-138.

29. Ploutz-Snyder LL, Giamis EL. Orientation and familiarization to 1RM strength testing in old and young women. J Strength Cond Res. 2001; 15(4):519-523.

30. Robles PG, Mathur S, Janaudis-Fereira T, Dolmage TE, Goldstein RS, Brooks D. Measurement of peripheral muscle strength in individuals with chronic obstructive pulmonary disease. J Cardiopulm Rehabil Prev. 2011;31(1):11-24.

31. Takai Y, Ohta M, Akagi R, Kanehisa H, Kawakami Y, Fukunaga T. Sit-to-stand test to evaluate knee extensor muscle size and strength in the elderly: a novel approach. J Physiol Anthropol. 2009;28(3):123-128.

32. Bernard S, LeBlanc P, Whittom F, et al. Peripheral muscle weakness in patients with chronic obstructive pulmonary disease. Am J Respir Crit Care Med. 1998;158(2):629-634.

33. Seymour JM, Spruit MA, Hopkinson NS, et al. The prevalence of quadriceps weakness in COPD and the relationship with disease severity. Eur Respir J. 2010;36(1):81-88.

34. Phillips WT, Benton MJ, Wagner CL, Riley C. The effect of single set resistance training on strength and functional fitness in pulmonary rehabilitation patients. J Cardiopulm Rehabil. 2006;26(5):330-337.

35. Lord SR, Murray SM, Chapman K, Munro B, Tiedemann A. Sit-to-stand performance depends on sensation, speed, balance, and psychological status in addition to strength in older people. J Gerontol A Biol Sci Med Sci. 2002;57(8):M539-M543.35.
International Journal of COPD

\section{Publish your work in this journal}

The International Journal of COPD is an international, peer-reviewed journal of therapeutics and pharmacology focusing on concise rapid reporting of clinical studies and reviews in COPD. Special focus is given to the pathophysiological processes underlying the disease, intervention programs, patient focused education, and self management protocols.
Dovepress

This journal is indexed on PubMed Central, MedLine and CAS. The manuscript management system is completely online and includes a very quick and fair peer-review system, which is all easy to use. Visit http://www.dovepress.com/testimonials.php to read real quotes from published authors. 